\title{
Psychiatric symptoms are present in most of the patients with idiopathic normal pressure hydrocephalus
}

\author{
Sintomas psiquiátricos são encontrados na maioria dos pacientes com hidrocefalia de \\ pressão normal idiopática
}

Matheus F. Oliveira', João R. M. Oliveira ${ }^{2,3}$, José M. Rotta ${ }^{4}$, Fernando C. G. Pinto ${ }^{4}$

\begin{abstract}
Normal pressure hydrocephalus (NPH) is characterized by gait disturbance, dementia and/or urinary incontinence associated with dilation of ventricular system with normal opening cerebrospinal fluid pressure. Wide scientifical evidence confirms association between NPH and psychiatric symptoms. We selected 35 patients with idiopathic normal pressure hydrocephalus from January 2010 to January 2012 in a Brazilian tertiary hospital and performed a formal psychiatric evaluation to identify psychiatric disorders. Psychiatric disorders were present in $71 \%$ of these patients, especially anxiety, depression and psychotic syndromes. NPH patients may develop symptoms with frontal dominance, such as personality changes, anxiety, depression, psychotic syndromes, obsessive compulsive disorder, Othello syndrome; shoplifting and mania. Unusual appearances of NPH symptoms may hinder early diagnosis and consequently proper treatment.
\end{abstract}

Keywords: normal pressure hydrocephalus, psychiatry, symptoms.

\section{RESUMO}

A hidrocefalia de pressão normal (HPN) é caracterizada por distúrbios da marcha, demência e/ou incontinência urinária associada com dilatação do sistema ventricular e pressão de abertura do líquido cefalorraquidiano normal. Evidências científicas confirmam associação entre HPN e sintomas psiquiátricos. Foram selecionados 35 pacientes com hidrocefalia de pressão normal idiopática, de janeiro de 2010 a janeiro de 2012 em um hospital terciário brasileiro e realizada uma avaliação psiquiátrica formal para identificar transtornos psiquiátricos. Transtornos psiquiátricos foram detectados em $71 \%$ dos pacientes, principalmente depressão, ansiedade e síndromes psicóticas. Pacientes com HPN podem desenvolver sintomas com predomínio frontal, tais como mudanças de personalidade, ansiedade, depressão, síndromes psicóticas, transtorno obsessivo compulsivo, síndrome de Otelo, furtos e mania. Sintomas incomuns de HPN podem dificultar o diagnóstico precoce e o tratamento adequado.

Palavras-chave: hidrocefalia de pressão normal, sintomas, psiquiatria.

Normal pressure hydrocephalus (NPH) is a syndrome characterized by gait disturbance, dementia and urinary incontinence plus dilation of ventricular system due to disturbance of cerebrospinal fluid (CSF) circulation with normal CSF pressure ${ }^{1,2,3,4,5,6}$. Dilated ventricles theoretically impair perfusion in ventricular walls, generating hypoperfusional states especially in frontal lobes, basal ganglia and thalamus, thus resulting classic symptomatology ${ }^{7}$.

$\mathrm{NPH}$ can present in two forms: primary (also known as idiopathic), when there are no causative disorders and secondary, where other disorders such as trauma, infection and hemorrhage are putative causes for hydrocephalus $^{1,2,3,4,5,6}$. Idiopathic NPH (INPH) is associated with communicating hydrocephalus (as demonstrated by brain CT or MRI) and CSF pressure within normal range $(7-24 \mathrm{~cm}$ $\mathrm{H} 2 \mathrm{O})^{1,2,3,4,5,6}$.

With improvements in quality of life and subsequent increase in life expectancy, it is expected that a greater number of elderly individuals will suffer from this disease. In 2008, incidence and prevalence of INPH were calculated in

\footnotetext{
${ }^{1}$ Programa de Residência em Neurocirurgia, Departamento de Neurocirurgia, Hospital do Servidor Público Estadual de São Paulo, Sao Paulo SP, Brazil;

${ }^{2}$ Laboratório Keizo Asami, Universidade Federal do Recife, Recife PE, Brazil;

${ }^{3}$ Departamento de Neuropsiquiatria, Universidade Federal do Recife, Recife PE, Brazil;

${ }^{4}$ Departamento de Neurocirurgia, Hospital do Servidor Público Estadual de São Paulo, Sao Paulo SP, Brazil.

Correspondence: Matheus Fernandes de Oliveira; Rua Pedro de Toledo, 1800; 04039-004 São Paulo SP, Brasil; E-mail: mafernoliv@yahoo.com.br

Conflict of interest: There is no conflict of interest to declare.

Received 01 August 2013; Received in final form 05 March 2014; Accepted 26 March 2014
} 
a stable community of 220,000 inhabitants in Norway, with values of 5.5/100,000 and 22/1,000,000, respectively ${ }^{2,3}$.

Identification of patients with INPH and implementation of effective treatment for INPH are current challenges for physicians and neurosurgeons. INPH is a disorder classified as a type of dementia that affects elderly and can be reversed if promptly diagnosed and treated ${ }^{1,2,3,4,5,6}$.

There is wide scientifical evidence pointing association between normal pressure hydrocephalus and psychiatric symptoms ${ }^{8,9,10,11}$. This study aims to recall main psychiatric involvements in NPH patients and describe specific experience of patients with idiopathic normal pressure hydrocephalus from Hospital do Servidor Público Estadual de São Paulo.

\section{METHOD}

We selected consecutively 35 patients with diagnosis of idiopathic normal pressure hydrocephalus from January 2010 to January 2012 in a Brazilian tertiary hospital. They were users of this medical facility screened in Hospital wards and forwarded by neurologists, geriatricians, psychiatrists and other specialities. Project was approved by Research and Ethic Committee.

Accepted diagnostic criteria were: clinical syndrome consistent with Adams-Hakim (gait apraxia, urinary incontinence and dementia) associated with ventricular dilatation documented by cranial CT and MRI scans. A positive Tap Test (TT) in at least one of two occasions was also needed. Inclusion criteria: diagnosis of idiopathic NPH, absence of malignant disease, clinical comorbidities (hypertension, diabetes mellitus, hormonal disorders, etc.) compensated. Exclusion criteria: diagnosis of secondary $\mathrm{NPH}$, inability to walk, malignancy, uncontrolled clinical comorbidities.

To select patients, we considered typical clinical settings, such as urinary incontinence, gait disturbance and dementia and compatible image studies associated to clinical response to TT. All patients underwent clinical evaluation, which consists of Mini-Mental State Examination (MM) and Time Up and Go (TUG) tests and application of Japanese Scale for Idiopathic Normal Pressure Hydrocephalus (JSINPH). All patients were submitted to imaging studies (CT scan and MRI of skull with CSF flow study), to screen for secondary causes of hydrocephalus. Standard measure used to determine concept of hydrocephalus was Evans Ratio (ER), which consists in dividing distance between frontal horns of lateral ventricles to maximal biparietal diameter. An ER value $>0.3$ is compatible with ventriculomegaly.

Additionaly, a formal psychiatric evaluation with the Mini-International Neuropsychiatric Interview was performed by a psychiatrist in all patients in order to identify psychiatric syndromes.
We have also performed a thorough review about the topic in Medline, Embase, Scielo and Lilacs databases. The keywords employed were "normal pressure hydrocephalus" OR "idiopathic normal pressure hydrocephalus" AND "psychiatry" OR "psychiatric" OR "neuropsychiatry" OR "neuropsychiatric". We selected all papers discussing about the above themes. We have excluded manuscripts discussing about other types of hydrocephalus. The objective was to summarize current knowledge about psychiatric symptoms in patients with normal pressure hydrocephalus, especially idiopathic type.

\section{Statistics}

In this study, numerical data are presented as mean \pm standard deviation or median with range when appropriate. Categorical data are presented as percentages. When comparing groups the level of significance will be considered when $\mathrm{p}<0.05$. To determine the distribution of our data, we used Kolmogorov-Smirnov Test. Statistical analysis for parametric variables was performed using Student's $t$-test for paired and unpaired groups, when appropriate. For non parametric variables, Chi Square test was applied. To perform evaluation between Evans Ratio and Mini Mental Scores, we applied Pearson's coefficient.

\section{RESULTS}

\section{Characterization of patients}

35 patients were evaluated in sample ( 15 females and 20 males). Mean age was $75.30 \pm 7.65$. Mean age of female group

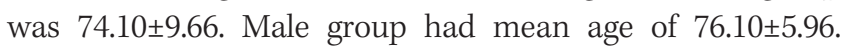
Both groups presented no etary statistically different significance $(\mathrm{p}>0.05)$

2 patients were illiterate, 5 patients had from 1 to 4 years of school, 10 had from 5 to 8 years of school, 13 had from 9 to 11 years of school and 5 had over 11 years, with an average of approximately 6.5 years of school.

From 35 patients, 25 presented with psychiatric syndromes (Group A). Depression-anxiety syndromes were assessed in 17 patients (10 women and 7 men), followed by psychotic syndromes ( 5 men and 2 woman) and bipolar disorder (1 woman). Total prevalence of psychiatric syndromes was $71.42 \%$, being $60 \%$ among men and $86 \%$ among women, with significant statistical difference between genders $(\mathrm{p}<0.05)$. Before this evaluation, only 6 patients $(5$ women and $1 \mathrm{man}$ ) attended to regular previous psychiatric evaluations due to depression-anxiety syndromes, 4 (2 men and 2 women) due to psychotic syndromes and 1 due to bipolar disorder.

Mean Evan's ratio was 0.37 with SD of 0.03, with no statistically difference between females and males. There was no linear correlation of ER with MM ( $p>0.05)$. 
Mean Mini Mental was 19 before TT and 21 after TT, with statistical difference $(p=0.01)$. Dividing Mini Mental domains, the scores before TT were 8 in time and place orientation, 3 in immediate memory, 1 in calculation, 1 in recall and 5 in language and commands. After TT, the scores were respectively $8,3,2,1$ and 6 .

Mean Japanese Scale was 6 before TT and 5 after TT, with statistical difference $(p=0.001)$. Mean TUG was 41 seconds before and 36.41 seconds after TT, with statistical difference ( $\mathrm{p}=0.003$ ). Mean CSF pressure was $152 \mathrm{mmHg}$ before and 29 mmHg after TT.

Comparing groups with (Group A) and without psychiatric symptoms (Group B), there were no statistically significant differences in ER, MM, JSINPH and TUG ( $\mathrm{P}>0.05)$.

\section{DISCUSSION}

It is already stated that patients with NPH may exhibit certain neuropsychiatric symptomatology $8,9,10,11$, possibly related to alterations in central neurotransmitter activity ${ }^{12}$. $\mathrm{NPH}$ patients may develop symptoms with frontal dominance, such as personality changes; anxiety; depression; psychotic syndromes, like delusional states, hallucinations and aggressive states; obsessive compulsive disorder; Othello syndrome; shoplifting and mania ${ }^{13,14,15,16}$. Basal ganglia symptoms are exemplified by chorea ${ }^{17}$. Thalamic symptoms may be exemplified by apathy and Othello syndrome, which is a content-specific delusion characterized by fixed false belief that one's partner has been or is being unfaithful ${ }^{16}$.

Just one manuscript was addressed specifically to INPH patients, finding that most frequently observed neuropsychiatric symptoms in INPH patients were apathy followed by anxiety and aggression ${ }^{11}$, meeting the profile of presented sample.

In the limited casuistic presented, $71 \%$ of patients diagnosed with INPH had some psychiatric follow-up, with predominance of apathic/depressed symptoms. In other words, more than eventual findings, psychiatric symptoms are typical in NPH patients.

Additionally, there was no correlation among ventricular size (Evans Ratio) and degree of cognitive impairment according to MM and there were no statistically significant differences in ER, MM, JSINPH and TUG between patients with and without psychiatric symptoms. This may be a biased result of our study or may also point towards other concepts of individual features, like scholarship, professional and daily activities, health patterns, quality of care, physical performance and most of all, individual functional reserve.

There is a paramount question regarding depressive syndromes among NPH patients. There is doubt if depressive symptoms are consequence to a primary disturbance in frontal neurotransmitter machinery ${ }^{12}$ or if symptoms are a result of self conscience of limited motor, continence and cognitive abilities, representing a burden to himself and to the family, thus leading to chronic sad humor ${ }^{18}$.

Unusual appearances of NPH symptoms may hinder early diagnosis and consequently proper treatment $t^{5,6,7}$. Sometimes, even response to typical treatment in psychiatric syndromes may be impaired, like a described patient having schizophrenia with intolerance to even low dose of antipsychotics, who was subsequently revealed to be having communicating normal pressure hydrocephalus ${ }^{19,20}$.

We did not evaluate a control group without NPH in order to compare our findings in idiopathic NPH patients. Once depression and anxiety are commonly observed in the elderly, this certainly must be a bias of the present essay. However we believe that such finding may be a weakness but may not invalidate our results.

Unfortunately, we did not apply in this opportunity a multidisciplinary team approach, with participation of neurologists, geriatricians, physiotherapists and occupational therapists. We also did not evaluate evolution of psychiatric symptoms after diversion procedure. Additionally, our statements are initial observations of a phenomenon that must be probably more frequent than usually believed. Those biases and weaknesses must be considered and aimed in future projects.

As disclosed above, psychiatric symptoms are common in the context of idiopathic NPH. We believe that an important portion of NPH patients may be attending to psychiatric evaluations. In the context of this manuscript, it is crucial for the psychiatrist to identify atypical cases and use neuroimage with skull computadorized tomography and/or magnetic resonance to clarify diagnosis.

In conclusion, idiopathic normal pressure hydrocephalus may manifest as psychiatric symptoms and syndromes thus being considered in differential diagnosis of daily patient evaluation, especially in atypical cases and those added to gait apraxia and urinary incontinence.

\section{References}

1. Ishikawa M, Hashimoto M, Kuwana N, et al. Guidelines for management of idiopathic normal pressure hydrocephalus. Neurol Med Chir (Tokyo) 2008;48(Suppl):S1-S23.

2. Pinto FC, Saad F, de Oliveira MF, et al. Role of Endoscopic third ventriculostomy and ventriculoperitoneal shunt in idiopathic normal pressure hydrocephalus: preliminary results of a randomized clinical trial. Neurosurgery 2013;72:845-854.

3. Pinto FC, de Oliveira MF. Response to journal club: role of endoscopic third ventriculostomy and ventriculoperitoneal shunt in idiopathic normal pressure hydrocephalus: preliminary results of a randomized clinical trial. Neurosurgery 2013;73:911-912. 
Oliveira MF, Saad F, Reis RC, Rotta JM, Pinto FCG. Programmable valve represents an efficient and safe tool in the management of idiopathic normal pressure hydrocephalus patients. Arq Neuropsiquiatr 2013;71:229-236.

5. Marmarou A, Bergsneider M, Klinge P, Relkin N, Black PM. The value of supplemental prognostic tests for the preoperative assessment of idiopathic normal-pressure hydrocephalus. Neurosurgery 2005;57 (Suppl):S17-S28.

6. Relkin N, Marmarou A, Klinge P, Bergsneider M, Black PM. Diagnosing idiopathic normal-pressure hydrocephalus. Neurosurgery 2005;57 (Suppl):S4-S16.

7. Oliveira MF, Pinto FCG, Nishikuni K, Botelho RV, Lima AM, Rotta JM. Revisiting hydrocephalus as a model to study brain resilience. Front Hum Neurosci 2011;5:181.

8. Pinner G, Johnson H, Bouman WP, Isaacs J. Psychiatric manifestations of normal-pressure hydrocephalus: a short review and unusual case. Int Psychogeriatr 1997;9:465-470.

9. Alao AO, Naprawa SA. Psychiatric complications of hydrocephalus. Int J Psychiatry Med 2001;31:337-340.

10. Lindqvist $G$, Andersson $H$, Bilting M, Blomstrand C, Malmgren $H$, Wikkels $\varnothing$ C. Normal pressure hydrocephalus: psychiatric findings before and after shunt operation classified in a new diagnostic system for organic psychiatry. Acta Psychiatr Scand 1993;373(Suppl):S18-S32.

11. Kito Y, Kazui H, Kubo Y, et al. Neuropsychiatric symptoms in patients with idiopathic normal pressure hydrocephalus. Behav Neurol 2009;21:165-174.

12. Markianos M, Lafazanos S, Koutsis G, Sfagos C, Seretis A. CSF neurotransmitter metabolites and neuropsychiatric symptomatology in patients with normal pressure hydrocephalus. Clin Neurol Neurosurg 2009;111:231-234.

13. Mclntyre AW, Emsley RA. Shoplifting associated with normalpressure hydrocephalus: report of a case. J Geriatr Psychiatry Neurol 1990;3:229-230.

14. Kwentus JA, Hart RP. Normal pressure hydrocephalus presenting as mania. J Nerv Ment Dis 1987;175:500-502.

15. Bloom KK, Kraft WA. Paranoia - an unusual presentation of hydrocephalus. Am J Phys Med Rehabil 1998;77:157-159.

16. Yusim A, Anbarasan D, Bernstein C, et al. Normal pressure hydrocephalus presenting as Othello syndrome: case presentation and review of the literature. Am J Psychiatry 2008;165:1119-1125.

17. Voermans NC, Schutte PJ, Bloem BR. Hydrocephalus induced chorea. J Neurol Neurosurg Psychiatry 2007;78:1284-1285.

18. Kazui H, Mori E, Hashimoto M, Ishikawa M, Hirono N, Takeda M. Effect of shunt operation on idiopathic normal pressure hydrocephalus patients in reducing caregiver burden: evidence from SINPHONI. Dement Geriatr Cogn Disord 2011;31:363-370.

19. Keenan S, Mavaddat N, Iddon J, Pickard JD, Sahakian BJ. Effects of methylphenidate on cognition and apathy in normal pressure hydrocephalus: a case study and review. $\mathrm{Br} J$ Neurosurg 2005;19:46-50.

20. Mishra BR, Sarkar S, Mishra S, Praharaj SK, Mahapatra P, Sinha VK. Antipsychotic sensitivity in normal pressure hydrocephalus. Gen Hosp Psychiatry 2011;33:83:11-13.

21. Boggio PS, Fregni F, Bermpohl F, et al. Effect of repetitive TMS and fluoxetine on cognitive function in patients with Parkinson's disease and concurrent depression. Mov Disord 2005;20:1178-1184. 